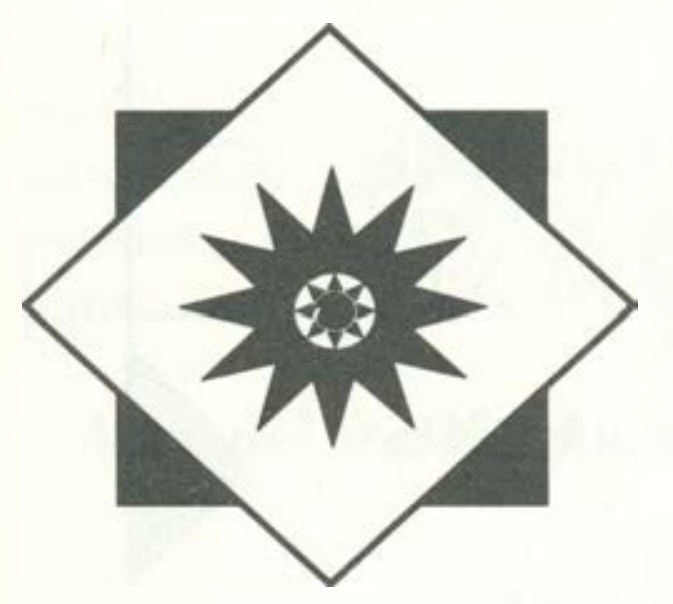

\title{
INNOVATIONS
}

\section{Humor and creativity: Reports from the field (1)}

\author{
By Norman D. Stevens
}

Director

The Molesworth Institute

In previous columns I have largely developed themes that demonstrate how individuals and individual libraries have made creative use of humor in dealing with particular events (e.g., holidays) or issues (e.g., preservation) or in a particular fashion (e.g., poetry). Each of those themes was selected by an osmotic process that involved sorting through an accumulation of material filed in random order and culling our items that seemed to fit together. The most recent sorting process failed, for unknown reasons, to identify a particular theme. Rather it mysteriously set forth a miscellaneous assortment of items that can best be described as reports from the field. Those reports come in such diverse forms as letters describing particular anecdotes, selections from newsletters real and imaginary, electronic mail messages, articles from obscure journals, and articles seeking a home. Together they demonstrate that academic, and even other, librarians are indeed creative souls and that library humor, which can take many forms, is alive and well. Just as the best library humor sometimes is nonsense that makes no sense, so this column and the next will be simply a potpourri designed for your entertainment. Enjoy!

\section{Reports}

Bored, or distressed, by the usual regular administrative chore of producing yet another annual report, set of goals and objectives, mission statement, or list of priorities, a few librarians eventually revolt. What use, they ask, is another generic document that reads as though it could have been produced at any other academic library? What value, they wonder, is a lofty set of statements describing events that never happened or never will? Why, they think, spend so much time producing another document that will be filed, not read? The fortunate result is the production of a few far more realistic, and certainly more entertaining, documents that, in the vernacular, tell it like its is. Not widely circulated, but deserving wider recognition, such organizational reports are among our real treasures. Three such underground documents have come to my attention recently. What is most fascinating is that two of these documents are not of recent vintage; they, unlike their real-life counterparts that are promptly filed and forgotten, obviously remain fresh in the minds and memories of a library's staff.

The first is a set of library projections for 1973 from an unnamed library. Allegedly based on interviews with various members of the library staff, it sets forth in two pages ten simple goals for various divisions and units. The Humanities Division, for example, hopes to be able to distribute 500 plaster busts of Aristophanes (received as a gift from the Shell Service Station) around the campus "to raise the intellectual level of this place." Other projections include: further experiments in the microfilming of students; the completion of 100,000 book requests-90\% marked rush-in 50 weeks; hiring 200 more staff for the acquisitions department to handle the 40 cubic yards of free material received weekly and to avoid having to buy 15 copies of every expensive book requested in order to spend the book budget; a sizable individual salary rebate resulting from a cost/benefit analysis revealing that "everyone in the library earning more than $\$ 10,000$ per annum is an unjustifiable overhead"; and even an effort to locate the director. 
A similar early document, drafted naturally by an interim director, from a named library that shall remain unnamed, outlines its mission and 18 goals. The proposed mission is "to provide enough information and spread it around sufficiently so the librarians won't get sued by the rest of the University for non-support." The goals are similarly succinct and to the point. They include: "to create an atmosphere which will lead patrons to come over and annoy us only when they have to; to let the world know what a good outfit we are; to put up enough signs on the library walls so all who enter will ultimately exit; to initiate at least one new list per librarian each day and one new file each week; and to develop a 10-year Long-Range Plan for monthly refreshments."

A more recent contribution comes in the form of Lemur T. Stodge's 1988/1989 annual report from the Moriarity Library at Claxton-Whimsey College in Amorphous, North Carolina. The report mainly describes the results of a third consecutive year of the institution's unique No Growth Library Budget policy. It is noted that only twenty percent of Stodge's time was spent in protesting the implementation of that policy in 1988/1989, as compared with fifty and seventy percent in the two preceding years, in large part because much of the rest of his time was spent in fulfilling the duties formerly assigned to the public service staff.

The entire nine-page report is filled with splendid examples of the ingenuity of Stodge and his few remaining staff and of how, in fact, the no-growth policy may have been a blessing in disguise. For example, in addition to surreptitiously canceling numerous periodical subscriptions, user frustration at not being able to find material has been reduced by canceling several indexing services as well. The simultaneous cancellation of the bibliographic instruction program is projected to eliminate informed student demand for periodicals after the graduation of the class of 1990 in any case. After much planning over several years Stodge has devised an ingenious scheme that would seem to solve the library's space problems, which remain severe despite a drastic decline in purchases, and faculty complaints about the potential weeding of their old favorite volumes. Many of those volumes were sent to faculty offices in 1987/1988 and in 1988/1989 the relevant cards were withdrawn from the catalogs. Regular reminders are now sent to the faculty asking them to return those volumes. "Given the fact that faculty members relentlessly ignore all such reminders, we have guaranteed the permanent removal of these titles from the premises, leaving adequate space for new books in the stacks." A variety of other efforts to reduce demand and services will allow the director to devote fewer hours each week to record-keeping, production of overdue notices, and shelving so that he will be able to spend more time reviewing job ads in the Chronicle of Higher Education.

\section{Newsletters}

The internal library newsletters, and their parodies, that were dealt with in detail in an earlier column (C\&RL News, January 1989) remain perhaps the richest source of academic library humor. While it is incredibly boring to read these in large doses, partly because they are often so poorly written and edited, but primarily because they tell you more than you care to know about local library events and people in whom you have no interest, they are always worth scanning for the occasional nuggets of intentional or unintentional humor that they contain. Their sloppy editing often produces gems that are worthy of inclusion in the "Marginalia" column of the Chronicle of Higher Education. Mosaic, from the University of Notre Dame Library, indicated recently, for example, that several staff had been on a "sight" visit to other libraries to investigate their signs. When new signs are in place in the library at Notre Dame it will surely be a "site" for sore eyes. For the inveterate collector of librariana, these newsletters often announce the availability of such treasures as library cookbooks or tshirts. My goal is not to acquire the world's largest collection of academic library internal newsletters, but I remain interested in acquiring on a regular basis those that feature intentional humor on a regular basis. I am especially interested in continuing to acquire on a regular basis parodies issued to celebrate April Fool's Day or other important occasions, such as the departure or arrival of a new director, for a permanent collection of such imaginary delights.

Even items that dwell on our former stereotype can be enjoyable if properly structured. The April 1, 1990, issue of the University of Louisville Library's The Ekspress, whose motto is "All the news that's print to fit," was not, alas, a true April Fool's issue but does contain one such gem in the guise of an ad-submitted by a reader who wanted to keep his identity quiet-for a Professional Shoosher. "A Professional Shoosher is someone who shooshes and has their MLS. Lowering decibels is the primary responsibility of a PS. When several people congregate, decibel levels rise, at which time the PS is called to the rescue.... A PS is usually someone who keeps to her/himself, can emerge without much notice and can't stand crowds. Although there is a high turnover rate among Professional Shooshers [perhaps their voice boxes give way and they might benefit from shooshing lessons], it is a time-honored position and fulfills the expectations of society at large." The ad concludes with the usual affirmation of equal opportunity, noting that "Applicants will be consid- 
ered in spite of their wardrobe and/or sour disposition."

More entertaining, especially for those among us who get apoplexy when we promote the stereotype, are some recent examples from old and new

\section{Feeling funny?}

You too can be famous! Slowly but surely since my first column in this series appeared in March of 1988 academic librarians have responded to my continued appeals for examples of the creative use of humor in librarianship. I have developed a regular stable of contributors who keep me supplied with a wide assortment of delightful stuff. Periodically others send me the occasional item, and some of the best material in my growing file has come in over the transom, so to speak. More contributions from both old and new friends are welcome.

I am, in general, a firm believer in the notion that the best examples of library humor are those that are created spontaneously in response to the real, but hard to believe, events and incidents that occur in all libraries. It is difficult to be creative simply because you want to be. Still and all, though, there is a place for artificially stimulated creativity. I am, therefore, pleased to announce-strictly on an experimental basis - the first-and perhaps last-creativity and humor competition sponsored by The Molesworth Institute. Open to all academic librarians, and anyone else who cares to participate, the challenge is a simple one. You need only send me a brief description of one or more of the twelve mighty library labors that might face a contemporary Hercules as he, or she, seeks purification and preeminence. What are the golden apples of the Hesperidian Library? One or more appropriate prizes, including even appointment as a Fellow of The Molesworth Institute, will be awarded depending on the quality of the entries and/or the mood of the judge. The decision of the judge is temporary and subject to change. To be considered for reporting in a subsequent column entries must be received by April 1, 1991. No entries will be returned but all will be acknowledged. Paper entries, from the old-fashioned librarian, may be sent to me at 143 Hanks Hill Road, Storrs, CT 06268 , preferably accompanied by your business card signed and dated on the verso. Electronic entries, from the newfangled librarian, may be sent to me either via Bitnet at hbladm3@uconnvm or ALANET at ala1625, preferably accompanied by your electronic business card.-Norman D. Stevens.
April Fool's newsletters with such great titles as The Biblio-fobe, Libel Talk, Library Lie, and the Weakly Agenda. In every case the contents of the issue are worthy of the titles. They report on such important matters as the cancellation of an OPAC project after years of committee work, the requirement that librarians at public service desks acquire malpractice insurance, new cataloging rules that transcend the main entry concept, several improved techniques for recovering overdue books, the joy of night reference service, the Perfectly Integrated Information Environment, and keeping creditors at bay.

A few examples will suffice to demonstrate the inestimable value of telling the truth about our problems. At the San Diego State University Library, for example, with the demise of the online public access catalog project-just after the Library was nominated for inclusion in the Guinness Book of World Records for having 24 OPAC committees generate 542 pages of minutes in a single month-the Name Committee met in emergency session to quickly name the card catalog Guis Agrippa Clodius Pulchar, having finally concluded that the first choice for the OPAC name would have been C.A.R.D. (Computerized Algorithmic Relations Database) Catalog.

At the University of Richmond the report from the Universal Librarian's Office on the PIIE suggests the desirability of finally integrating food services and library services to accommodate, rather than discourage, student preference for eating and drinking while using the library. That, along with several other innovations, is part of a larger scheme to "bring all other services to our patrons while they remain in the library. The political advantages to us are clear: we retain control and increase dependency. Within two years we will not only be the 'heart and brain' of the University, we will have all the muscle we need to demand more funding and more respect." Go for it!

The Rutgers University Library contribution describes several efforts to raise new funds to offset an anticipated $36 \%$ loss in the projected budget including: a bake sale that raised more than $\$ 43$; the sale of the card catalog to another department in the university where it will be used to house small laboratory animals; the "All You Can Carry Sale" from the collection that netted $\$ 340$ and cleared 13,000 square feet of stack space; and the proposed Car-wash/Phonathon to call alumni urging them to wash their cars themselves and mail a check to the library. Through such efforts the Rutgers University Library is bound to "remain one of the premier library systems in Middlesex County." Driven to such desperate measures, the Rutgers University Library, like the University of Richmond Library, has decided to allow food and beverages in all its units. That includes the addition of a food delivery 
service (either B-U-Y P-I-Z-A or E-A-T D-E-L-I) to the existing document delivery service via either the Food Fone or the Food Fax machines designed to look like actual food items. The fine print at the end of the Rutgers newsletter sheds a great deal of light and truth on the real purposes of all library newsletters. It "is intended to provide information about library activities and other things that no one really wants to read about. Included are such items as: announcements, pronouncements, and denouncements; lies, damned lies, and statistics; retractions, corrections and recriminations; and more meetings than you can shake a stick at. 'People in the Library'. . . notes briefly such information as marriages, divorces, affairs, births, deaths, deportations, arraignments, indictments and incarcerations; lacerations, bumps, bruises and scrapes; and addictions, afflictions and other fictions."

Always sure to produce groans, puns and similar forms of wordplay, have only a limited audience.
Fortunately there do not appear to be an inordinate number of library punsters but there are, alas, a few who deserve at least brief mention. Irving Weintraub, of the Rutgers University Library (is something going on there?), sent me a single-page sheet that contains, among other faults, the following sample of his "wit." If Harrison Ford had been a librarian he would have been searching for cataloging records rather than diamonds in Readers of the Lost MARC. The difference between a reference librarian and a rebellious youth is that one is an authority on questions and the other questions authority. Librarians usually refer to journals that represent an industry or discipline as an organ; that sometimes causes embarrassment for agricultural librarians who may refer to a journal dealing with a breed of livestock as the "breed organ." Weintraub once ended up describing a journal as "an organ for the dissemination of information on insemination."

More next time.

\title{
Adventures in grant-writing
}

\author{
By Ada D. Jarred
}

Director of Libraries

Northwestern State University of Louisiana

In a recent issue of College \& Research Libraries News, Sherman Hayes called for reports on "unique, weird services" in academic libraries. ${ }^{1}$ The librarians of Northwestern State University of Louisiana disagree somewhat with Hayes's taxonomy of activities but are nevertheless eager to share their recent adventures in writing grants.

Louisiana's depressed economic conditions over the last several years have necessitated alternative funding to maintain and enhance the core services of Eugene P. Watson Memorial Library, Northwestern State University of Louisiana. Naturally, thoughts of Northwestern librarians turned to the writing of grant proposals. Several applications proved successful, leading to the development of unusual services which have enriched the university and the surrounding area, as well as assisted with the support of core activities.

Not the least among the delights of Northwestern State University is its setting in Natchitoches (NAK-o-tish), Louisiana, the oldest continuous

${ }^{1}$ Sherman Hayes, "Wanted: Weird and/or Unusual Services and Activities," C $\measuredangle R L$ News 51 (April 1990): 322-325.
European settlement in the Louisiana Purchase and the central city of the Cane River region, a culturally diverse area of northwest Louisiana. One of the fascinating former residents of Natchitoches Parish (county) was the celebrated American author Kate Chopin, who devoted much of her writing to the people and life of this area.

In 1988 the NSU director of libraries agreed to be project director of the first international conference devoted to the life and works of Chopin. The meeting was created and planned by faculty members of the NSU Department of Languages and Communications; the NSU Louisiana Folk Life Center; the Louisiana Scholars' College, an interdisciplinary program for academically advanced university students of high ability; and the Louisiana School for Math, Science and the Arts, a residential high school for gifted and talented juniors and seniors. This was the first cooperative effort between these entities, all of whom are located on the same campus. The Association for the Preservation of Historic Natchitoches, owner and operator of the Bayou Folk Museum (housed in Chopin's former home) in nearby Cloutierville, also was a participating sponsor. 